\title{
Diapause behaviour of Zygogramma bicolorata (Coleoptera: Chrysomelidae), a biological control agent for Parthenium hysterophorus (Asteraceae), in Bangalore, India
}

\author{
K.P. Jayanth \\ Division of Entomology and Nematology, Indian Institute of Horticultural \\ Research, Bangalore, India
}

Geetha Bali

Department of Zoology, Bangalore University, India

\begin{abstract}
Zygogramma bicolorata Pallister was introduced for biological control trials against the weed Parthenium hysterophorus (Asteraceae) in India. The insect entered diapause over an extended period of time between July and December in Bangalore. Diapausing adults burrowed into the soil, and emerged in MayJune with the commencement of monsoon rains. Percentage diapause increased over time, peaking at $72 \%$ during November. Non-diapausing adults were capable of breeding, under laboratory conditions, during the winter. Some adults bred both before and after diapause, during two consecutive years. Soil moisture played an important role in providing the conditions for burrowing or emerging from the diapause chambers. The studies also showed that diapausing adults had to be exposed to the high summer temperatures, for termination of the diapause. It was possible to break diapause by continuous exposure to $30^{\circ} \mathrm{C}, 35^{\circ} \mathrm{C}$ and $40^{\circ} \mathrm{C}$ for 22 days, nine days and 10 hours, respectively, during February-March, about three months after its inception. This method can be used to initiate mass multiplication for carrying out releases early in the season.
\end{abstract}

Introduction

The allergenic weed Parthenium hysterophorus (Asteraceae) grows under diverse climatic conditions in many countries in Africa, Asia and Australia (Towers et al., 1977). The Mexican beetle Zygogramma bicolorata Pallister (Coleoptera: Chrysomelidae) established readily in Bangalore, after releases were initiated in 1984 (Jayanth, 1987). It appears to have potential in permanently reducing the weed density in Bangalore and the surrounding areas. The insect remains active between June and October and undergoes diapause as adults, within the soil, between November and May.

Large scale field releases with $Z$. bicolorata have now been initiated in different parts of India. The ability of the

Correspondence: K.P. Jayanth, Division of Entomology and Nematology, Indian Institute of Horticultural Research, Hessaraghatta Lake Post, Bangalore-560089, India. insect to synchronize its period of activity to the availability of its plant host is likely to play a major role in its establishment and effectiveness as a biological control agent in new areas of colonization. The timing of the onset, maintenance and termination of diapause, as also of post diapause development and reproduction, could determine successful adaptation to new areas.

Although studies were carried out on the biology of $Z$. bicolorata in Mexico and Australia (McClay, 1980, 1985; McFadyen \& McClay, 1981; McFadyen, 1992), no information is available on diapause. During the present studies the diapause behaviour of the insect was examined, and the role of certain environmental and biological factors in inducing and terminating diapause, as well as the effect of diapause on the biology of the insect, were investigated. 


\section{Materials and methods}

Studies on diapause in $Z$. bicolorata were carried out in cages prepared as follows; air dried, field collected soil (sandy clay loam - Udic Haplustalf) was collected into clear plastic jars $(11 \times 14 \mathrm{~cm})$ and compressed by pounding with a wooden rod to get a $5 \mathrm{~cm}$ column of soil. Water was added in quantities just sufficient to moisten the soil column, except where indicated below.

For the purpose of the present studies, burrowing was used as a behavioural indicator for the occurrence of diapause. For studies on diapause behaviour under natural conditions, about 100 adults were collected from the field at fortnightly intervals from 16 June to 15 December 1989. They were fed for one week in laboratory cages and then released into four diapause cages without food and monitored for one more week. Preliminary studies had indicated that diapausing adults burrowed into the soil within five days when deprived of food. Therefore, all adults which burrowed into the soil within one week were counted as being in diapause.

The above studies were repeated in 1990 with laboratory reared adults. For this experiment newly emerged adults were collected from the field in May 1990 and cultured in the laboratory. Temperature, humidity and photoperiod were not regulated and field collected leaves of Parthenium were provided for feeding once in two or three days. About 50 one-month-old adults from each generation were then tested for initiation of diapause.

To study the role of moisture in initiating burrowing, 25 adults each were released in two diapause cages. The soil in one of the cages was oven dried for 24 hours at $40^{\circ} \mathrm{C}$, while that in the other was moistened. In another experiment 25 field collected adults each were allowed to diapause in 10 cages during October 1990. Water was then sprinkled into one cage once a month, from November 1990 to August 1991, to study the role of soil moisture in the emergence of adults from diapause.

Studies were also carried out on the role of excess moisture in inducing emergence, by saturating the soil in diapause cages with water, during February-May 1991. In addition, adults removed from diapause chambers in the soil were released into cages with moist or dry soil with food, during the same period, to determine whether or not they can be induced to resume activity.

Twenty-five field collected adults each were released in three diapause cages placed in Biological Oxygen Demand incubators maintained at $15^{\circ} \mathrm{C}, 25^{\circ} \mathrm{C}$ and $35^{\circ} \mathrm{C}$, respectively, and observed for initiation of diapause. These studies were carried out during October 1990. Cages containing 25 diapausing adults were also exposed to low $\left(0^{\circ} \mathrm{C}\right.$ and $\left.5^{\circ} \mathrm{C}\right)$ and high $\left(30^{\circ} \mathrm{C}, 35^{\circ} \mathrm{C}, 40^{\circ} \mathrm{C}\right.$ and $45^{\circ} \mathrm{C}$ ) temperatures for varying periods of time in December and February 1991 to determine whether temperature influenced emergence after diapause. In the high temperature treatment, observations were made at one day intervals, until emergence was noticed. At $40^{\circ} \mathrm{C}$ and $45^{\circ} \mathrm{C}$ additional studies were carried out by exposing diapausing adults for $2 \frac{1}{2}$, five, 10,15 and 20 hours. Studies were also carried out by exposing diapausing adults to these temperatures for $2 \frac{1}{2}$ hours every day for four days. Soil in cages with adults exposed to low temperatures was observed at monthly intervals for three months. In all cases involving temperature treatment, observations were carried out after moistening the soil to facilitate emergence.

Studies were also carried out to examine whether there is any correlation between the age of the adults, their nutritional and mating status, and the phenomenon of diapause. For determining the role of adult age in diapause induction, laboratory reared adults varying in age from just emerged to $15,30,45,60,75$ and 90 days old were released in seven different diapause cages, taking 25 adults in each. Adults that emerged during the last week of July 1990 were used for these studies. Similarly, mated and unmated adults were release into two diapause cages at the rate of 25 per cage to determine whether mating is essential to induce diapause.

The fecundity and longevity of 10 pairs of adults collected from the field in May 1989, soon after they had emerged from diapause, was determined. In addition, the fecundity and longevity of 10 pairs of adults that emerged from field collected pupae during July 1989 was also monitored. These adults were placed in pairs in rearing cages with moist soil. Leaves of Parthenium were provided on alternate days for feeding and oviposition. In cages where diapausing adults had burrowed, water was added during June 1990 to study emergence. The fecundity and duration of adult survival were again monitored.

The mean laboratory temperature and humidity were found to range between $21.25-31.50^{\circ} \mathrm{C}$ and $55-91 \%$ r.h. during the study period.

\section{Results}

Adults of Z. bicolorata burrow into the soil and diapause within the chambers they form about $1-3 \mathrm{~cm}$ beneath the surface. The egg, larval and pupal stages did not enter diapause.

\section{Diapause in field collected adults}

The results showed that these insects entered diapause any time from July to December (fig. 1). The percentage of adults entering diapause was found to increase with time, with a slight dip during September and early October, and a peak of $72 \%$ in the last week of

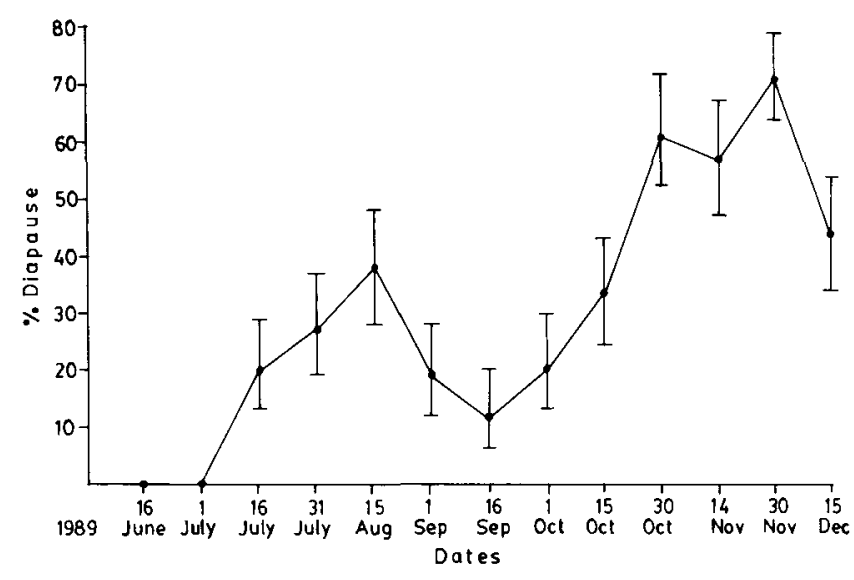

Fig. 1. Diapause of Zygogramma bicolorata adults collected at fortnightly intervals from the field. 


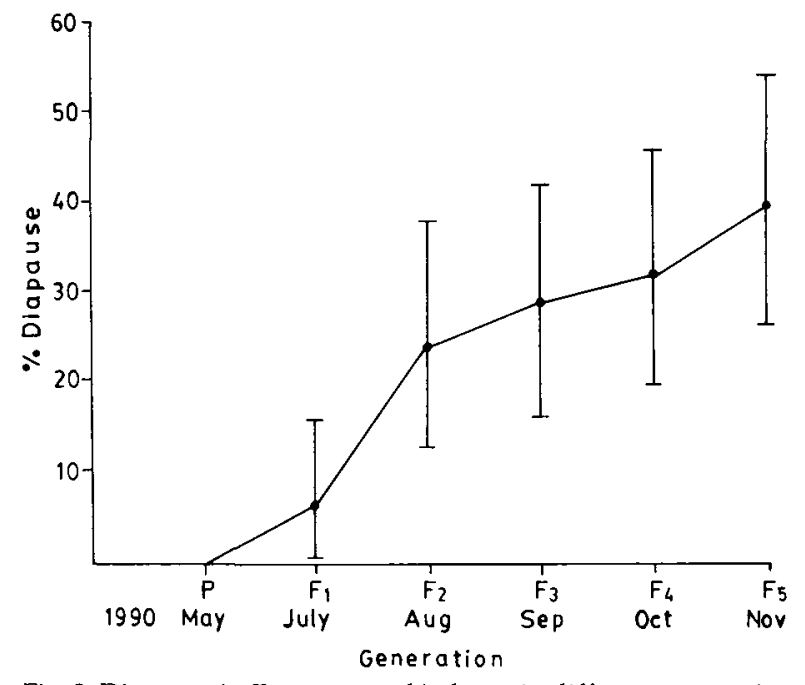

Fig. 2. Diapause in Zygogramma bicolorata in different generations when bred in the laboratory.

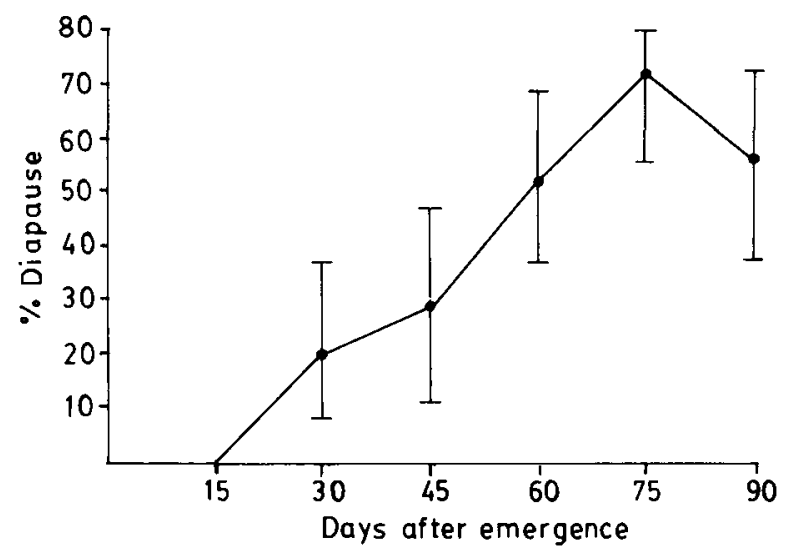

Fig. 3. Diapause of Zygogramma bicolorata in relation to age of adults.

November. None of the adults collected during May and June were observed to diapause.

When Z. bicolorata adults were collected from the field on 25 May 1990 and bred continuously in the laboratory the percentage of diapausing adults was found to increase with every generation (fig. 2). None of the adults collected from the field on 25 May entered diapause. In the first generation $6 \%$ of the adults burrowed into the soil, which increased to $24 \%$ during the second generation and peaked at $40 \%$ during the fifth generation.

\section{Influence of moisture and temperature}

Adults of $Z$. bicolorata could not penetrate dry soil for diapause, they attempted burrowing, without being able to penetrate, when the soil surface alone was moistened. Most of the adults collected during November, when the soil remained dry under field conditions, burrowed within two hours after they were given moist soil in the laboratory.
Adults emerged from diapause from May onwards under laboratory conditions, in response to soil moisture. Soil moisture did not induce emergence between November and April, even if the soil was kept moist throughout. Saturation of the soil resulted only in drowning of diapausing adults, not their emergence. When the adults were removed from their diapause chambers and again released on moist soil they burrowed in once again. In the absence of soil moisture such adults remained without feeding on the Parthenium leaves provided. Only adults removed from the diapause chambers during May resumed activity.

When adults of $Z$. bicolorata were collected from the field and released in diapause cages placed at $15^{\circ} \mathrm{C}, 25^{\circ} \mathrm{C}$ and $35^{\circ} \mathrm{C}$, respectively, $52 \%, 56 \%$ and $56 \%$ of them burrowed into the soil. These percentage differences were not significant.

Exposure to extreme low temperatures $\left(0^{\circ} \mathrm{C}\right.$ and $\left.5^{\circ} \mathrm{C}\right)$ did not cause mortality even after three months. However, at extreme high temperatures, there was $100 \%$ mortality after 10 days of continuous exposure to $40^{\circ} \mathrm{C}$ or 21 hours at $45^{\circ} \mathrm{C}$.

Exposure of diapausing adults to high temperature induced unseasonal emergence, if the treatment was carried out three months after they had burrowed into the soil. Studies carried out in February 1991 showed that exposure to $40^{\circ} \mathrm{C}$ for 10 hours, either continuously or in doses of $2 \frac{1}{2}$ hours every day, could induce emergence. Premature emergence from diapause could also be obtained by continuous exposure for nine days at $35^{\circ} \mathrm{C}$ or 22 days at $30^{\circ} \mathrm{C}$.

When diapausing adults were removed from the soil and exposed to $35^{\circ} \mathrm{C}$ they resumed activity in 10 days, indicating that it is the warm temperature and not the humidity which is responsible for the emergence. About two to four days were required for emergence to start when soil was moistened after high temperature treatment. It was also observed that high temperature induced emergence in only about $50-60 \%$ of the treated adults at all temperatures.

\section{Influence of certain biological factors}

Newly emerged adults were incapable of burrowing into the soil for diapause. None of the adults were observed to enter diapause during the first two weeks after emergence. The percentage of diapause increased with the age of the adult from the 30th (20\%) to the 75th (72\%) day, after which it declined (fig. 3).

Adults of $Z$. bicolorata that were ready to diapause mated before they entered the soil. However, mating was not a prerequisite for the initiation of burrowing as unmated females and males were also capable of diapause.

\section{Timing of reproduction in relation to diapause}

Adult females collected from the field, immediately after they had emerged from diapause in June 1989, survived for 78-128 days and laid 602-3655 eggs (table 1). Studies on a batch of adults of the $F_{1}$ generation after diapause, that had emerged on 11 July 1989, showed that $20 \%$ of the females entered diapause without any oviposition. They burrowed into the soil by the twenty-first day even though fresh leaves of Parthenium were provided on 
Table 1. Longevity and fecundity of Zygogramma bicolorata adults that emerged in the field after completing diapause.

\begin{tabular}{lccc} 
& \multicolumn{2}{c}{ Longevity (days) } & $\begin{array}{c}\text { Fecundity } \\
\text { (no. of eggs) }\end{array}$ \\
\cline { 2 - 3 } & Female & Male & \\
\hline 1 & 50 & 99 & 821 \\
2 & 133 & 88 & 2243 \\
3 & 53 & 85 & 981 \\
4 & 39 & 121 & 602 \\
5 & 85 & 165 & 1796 \\
6 & 102 & 92 & 1432 \\
7 & 82 & 123 & 1550 \\
8 & 105 & 182 & 1430 \\
9 & 130 & 78 & 3655 \\
10 & 90 & 162 & 1639 \\
Mean ( \pm SD) & $86.9 \pm 32.29$ & $119.5 \pm 37.83$ & $1614.9 \pm 864.09$ \\
\hline
\end{tabular}

alternate days for feeding. Similarly, $30 \%$ of the females did not undergo diapause at all and laid 1351-3542 eggs within 91-225 days (table 2).

The studies also showed that $50 \%$ of the females were capable of laying eggs both before and after diapause. These females laid 258-1169 eggs in 10-61 days, after which they entered diapause. After emergence from diapause they again laid 756-1274 eggs in 50-80 days.

Sixty percent of the females that emerged on 11 July 1989 survived for more than a year (382-416 days). This included the pre-diapause, diapause and post-diapause durations. Similarly the males also survived for a total of 400-407 days (table 2).

\section{Discussion}

The present studies have thrown light on the role of certain environmental and biological factors on the diapause behaviour of $Z$. bicolorata. However, diapause itself is a whole syndrome including behavioural, physiological, developmental and reproductive changes. Adults of $Z$. bicolorata are capable of entering diapause over an extended period of time between July and December, which probably makes it a more efficient biological control agent, especially in view of its feeding behaviour.

As in the case of Z. suturalis (Fabricius) attacking Ambrosia artemisiifolia (Asteraceae) in the USSR (Kovalev, 1988), Z. bicolorata defoliates Parthenium plants in a particular area and then migrates. As a result, by the end of the rainy season very few adults are likely to be present in the initial area of defoliation. However, since diapause takes place throughout the breeding season, some diapausing adults are left behind at each location, which are ready to tackle the recurrent growth of the weed during the following year. This eliminates the necessity of reintroduction of the beetle in the area where it was once introduced, if and when the weed density increases.

Polymorphism in the timing of diapause has been reported in the Colorado potato beetle, Leptinotarsa decemlineata (Say) (Coleoptera: Chrysomelidae) in the USA (Tauber et al., 1988). In this beetle diapause was noticed to commence in part of the population early in the summer and extended over a long period. Tauber et al. (1988) noted this was a mechanism to cope with unfavourable environmental conditions. Leptinotarsa decemlineata is a 'long day insect', which enters diapause after exposure to a critically short photoperiod. However, this beetle was also found to respond to senescing potato foliage or being fed with a less preferred host-plant (Hare, 1990).

It is not clear what triggers diapause behaviour in $Z$. bicolorata, especially since abundant food was available and weather conditions remained favourable during July to October (fig. 4). The temperature conditions remain more or less stable in Bangalore between June and October. Field temperature data collected over three years showed that the mean temperature during this period ranged between 22.85 and $25.65^{\circ} \mathrm{C}$. Similarly, monthly mean maximum and minimum temperatures also ranged between 27.0 and $28.6^{\circ} \mathrm{C}$ and 19.3 and $20.4^{\circ} \mathrm{C}$, respectively.

Zygogramma bicolorata entered diapause only once during its life time. Thus, none of the adults collected from the field during May and June entered diapause; the population during this period consisted mainly of adults that had emerged after diapause. Although the $F_{1}$ generation was also represented, these were probably too young and were not ready to enter diapause. Besides, laboratory studies clearly showed that adults younger than 15 days of age did not enter diapause. It was also observed that within a given generation, the percentage of adults entering diapause increased over time from $20 \%$ on the thirtieth day after emergence to $72 \%$ on the seventy-fifth day, thus indicating that there is no critical period in adult life for initiation of burrowing, as in the case of $L$. decemlineata (Tauber et al., 1988).

The percentage of field collected adults burrowing into the soil was found to increase progressively from July to November. The increase in diapause towards the end of the Parthenium growing season could be due to senescing host-plant foliage, as was reported by Hare (1990) in L. decemlineata. The reduction in the percentage of diapause observed during September and October could be due to the presence of many non-diapausing adults from previous generations. The results shown in figure 3, suggest that the onset of diapause would be strongly dependent on the age structure of the population at a given time.

The low percentage of diapause in adults maintained in the laboratory is probably due to partial masking of the environmental cues within the laboratory. The maximum percentage of diapause in laboratory reared insects in the $\mathrm{F}_{5}$ generation during November was only $40 \%$ whereas $72 \%$ of the adults collected from the field during the same period entered diapause.

As not all adults of $Z$. bicolorata entered diapause, it is debatable whether diapause in this insect can be categorized as 'obligatory'. However, since the surviving adults perished in the field by February, without reproducing, they may not qualify for inclusion under 'facultative' category either. Non-diapausing adults could breed under laboratory conditions, after about a month, when provided with fresh leaves of Parthenium.

Copulation has not been observed in the sunflower beetle $Z$. exclamationis (Fabricius) in Manitoba, Canada (Gerber et al., 1979) whereas adults of Z. bicolorata were observed to mate before diapause. Adults of Z. bicolorata showed variability in reproduction in relation to diapause 
Table 2. Longevity and fecundity of Zygogramma bicolorata before and after diapause in a population that emerged on 11 July 1989.

\begin{tabular}{|c|c|c|c|c|c|c|c|c|c|c|c|}
\hline \multirow[t]{3}{*}{ No. } & \multicolumn{8}{|c|}{ Longevity (days) } & & & \\
\hline & \multicolumn{4}{|c|}{ Females } & \multicolumn{4}{|c|}{ Males } & \multicolumn{3}{|c|}{ Fecundity (no. of eggs) } \\
\hline & $\begin{array}{c}\text { Pre- } \\
\text { diapause }\end{array}$ & Diapause & $\begin{array}{c}\text { Post } \\
\text { diapause }\end{array}$ & $\begin{array}{c}\text { Total } \\
\text { longevity }\end{array}$ & $\begin{array}{c}\text { Pre- } \\
\text { diapause }\end{array}$ & Diapause & $\begin{array}{c}\text { Post } \\
\text { diapause }\end{array}$ & $\begin{array}{c}\text { Total } \\
\text { longevity }\end{array}$ & $\begin{array}{c}\text { Pre- } \\
\text { diapause }\end{array}$ & $\begin{array}{c}\text { Post } \\
\text { diapause }\end{array}$ & Total \\
\hline 1 & 225 & 一 & 一 & 225 & 45 & + & - & 45 & 3543 & - & 3543 \\
\hline 2 & 19 & 315 & 71 & 405 & 51 & 285 & 64 & 400 & - & 2309 & 2309 \\
\hline 3 & 91 & - & - & 91 & 231 & - & - & 231 & 1351 & - & 1351 \\
\hline 4 & 56 & 277 & 72 & 405 & 97 & - & 一 & 97 & 1023 & 756 & 1779 \\
\hline 5 & 39 & + & - & 39 & 25 & + & - & 25 & 285 & - & 285 \\
\hline 6 & 50 & 288 & 74 & 412 & 64 & 270 & 70 & 405 & 346 & 800 & 1146 \\
\hline 7 & 132 & - & - & 132 & 55 & + & - & 55 & 1812 & - & 1812 \\
\hline 8 & 71 & 266 & 80 & 412 & 60 & + & - & 60 & 1169 & 1274 & 2443 \\
\hline 9 & 79 & 253 & 50 & 382 & 134 & - & - & 134 & 258 & 761 & 1019 \\
\hline 10 & 32 & 305 & 79 & 416 & 36 & 299 & 72 & 407 & - & 1742 & 1742 \\
\hline
\end{tabular}

+ No emergence after diapause.

within the same generation. Thus, about $20 \%$ of the adults that emerged in July 1989 were found to reproduce only during the following year, after completion of diapause. The prolonged survival of adults and their capacity to reproduce during two consecutive years is very significant from the point of view of survival in areas where rainfall is erratic.

Soil moisture was found to be important during diapause initiation as well as emergence, as it provides the physical conditions for successful burrowing or emergence from diapause chambers. Unseasonal rains during November to December may provide favourable conditions for burrowing. However, unseasonal rains up to April did not induce emergence from diapause. This indicates that, for the termination of diapause, adults have to be exposed to the higher temperatures which occur during summer.

It was observed during the present studies, that diapausing adults of Z. bicolorata can be induced to emerge from diapause by high temperature treatment. Such adults can be mass multiplied for carrying out releases in areas where the weed thrives during the off season, since they do not breed under natural conditions during this period. Insects that have been induced to emerge prematurely need to be investigated before use as agents for biological control of Parthenium, especially around irrigated fields and other areas where moisture will be available to facilitate reproduction.

Photoperiod plays an important role in the induction and termination of diapause in insects in temperate regions (Tauber \& Tauber, 1976). In temperate areas there is clear cut seasonal variation in temperature and daylength, which is absent in the tropics (Denlinger, 1986). Although day lengths do not vary greatly in the tropical regions of the world, meteorological data collected at

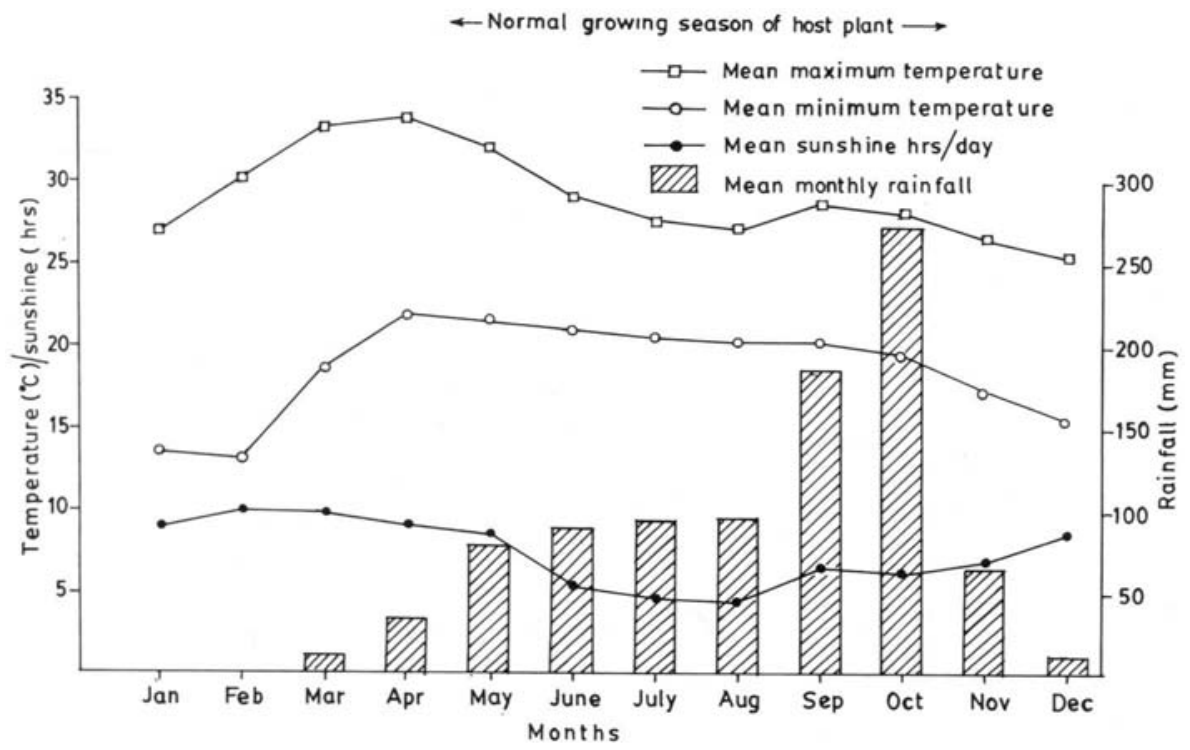

Fig. 4. Climate diagram for Bangalore for the period 1989-1991 showing mean monthly temperature, rainfall and sunshine hours per day. 
Bangalore during 1989 to 1991 showed variation in the mean sunshine hours per day (fig. 4). The role played by the latter in the diapause of $Z$. bicolorata would be very interesting for further investigation.

\section{Acknowledgements}

The authors are grateful to Dr R.M. Pandey, Director, Indian Institute of Horticultural Research, for encouragement given.

\section{References}

Denlinger, D.L. (1986) Dormancy in tropical insects. Annual Review of Entomology 31, 239-264.

Gerber, G.H., Neill, G.B. \& Westdal, P.H. (1979) The reproductive cycles of the sunflower beetle, Zygogramma exclamationis (Coleoptera: Chrysomelidae), in Manitoba. Canadian Journal of Zoology 57, 1934-1943.

Hare, J.D. (1990) Ecology and management of the Colorado potato beetle. Annual Review of Entomology 35, 81-100.

Jayanth, K.P. (1987) Introduction and establishment of $Z y$ gogramma bicolorata on Parthenium hysterophorus at Bangalore, India. Current Science 56, 310-311.

Kovalev, O.V. (1988) A new biological phenomenon: the solitary population wave, and its role in the biological control of pests, weeds in particular. Entomophaga 33, 259-260.

McClay, A.S. (1980) Preliminary report of the biology and host- specificity of Zygogramma sp. near malvae Stal. (Col., Chrysomelidae), a potential biocontrol agent for Parthenium hysterophorus L. 10 pp. Unpublished report, Commonwealth Institute of Biological Control, Monterry, Mexico.

McClay, A.S. (1985) Biological control agents for Parthenium hysterophorus from Mexico. pp. 771-778 in Del Fosse, E.S. (Ed.) Proceedings VI International Symposium on Biological Control of Weeds. Ottawa, Canada, Agriculture Canada.

McFadyen, R.C. (1992) Biological control against parthenium weed in Australia. Crop Protection 11, 400-407.

McFadyen, R.E. \& McClay, A.S. (1981) Two new insects for the biological control of Parthenium weed in Queensland. Proceedings of the 6th Australian Weeds Conference 1, 145-149.

Tauber, M.J. \& Tauber, C.A. (1976) Insect seasonality: diapause maintenance, termination and post-diapause development. Annual Review of Entomology 21, 81-107.

Tauber, M.J., Tauber, C.A., Obrycki, J.J., Gollands, B. \& Wright, R.J. (1988) Voltinism and the induction of aestival diapause in the Colorado potato beetle, Leptinotarsa decemlineata (Coleoptera: Chrysomelidae). Annals of the Entomological Society of America 81, 748-754.

Towers, G.H.N., Mitchell, J.C., Rodriguez, E., Bennett, F.D. \& Subba Rao, P.V. (1977) Biology and chemistry of Parthenium hysterophorus L., a problem weed in India. Journal of Scientific and Industrial Research 12, 672-684.

(Accepted 3 February 1993)

(C) C.A.B International, 1993 